\title{
The prospective COVID-19 vaccine: Willingness to pay and perception of community members in Ibadan, Nigeria
}

\author{
Olayinka Ilesanmi ${ }^{1,2}$, Aanuoluwapo Afolabi ${ }^{\text {Corresp., } 1}$, Obioma Uchendu ${ }^{1,2}$ \\ ${ }^{1}$ Department of Community Medicine, University of Ibadan, Ibadan, Oyo, Nigeria \\ 2 Department of Community Medicine, University College Hospital, Ibadan, Oyo, Nigeria \\ Corresponding Author: Aanuoluwapo Afolabi \\ Email address: afoannade@gmail.com
}

BACKGROUND. The ongoing development of the COVID-19 vaccine necessitates the assessment of individual perception regarding the vaccine. This study aimed to assess the perception of community members and willingness to pay for the prospective COVID-19 vaccine in Ibadan, Nigeria. METHODS. A descriptive cross-sectional study design was used. Data were collected using an interviewer-administered questionnaire in September 2020. We studied community members aged 15 years and above using a multi-stage sampling technique. The perceptions of respondents about COVID-19 were assessed on 8 questions using the five-point Likert scale with a score point of "1" assigned for "Strongly Agree", "2" for Agree", "3" for "Not decided", "4" for "Disagree", and "5" for "Strongly disagree". During analysis, we reverse-coded the options by assigning a point of " 1 " for "Strongly disagree", " 2 " for "Disagree", " 3 " for "Not decided", "4" for "Agree", and "5" for "Strongly disagree". However, questions asked in the negative directions were not reverse-coded during analysis. Eight questions were used to assess the perception of community members regarding the prospective COVID-19 vaccine, and overall, the maximum point was 40 . Points greater than or equal to $\geq 32$ points ( $80 \%)$ implied positive perception. Descriptive statistics were done. Chi-square tests were used for the assessment of associations between sociodemographic characteristics and willingness to pay for the prospective COVID-19 vaccine. We conducted logistic regression tests on statistically significant variables at $p$-values $<0.05$. RESULTS. The mean age of the 440 respondents studied was $37.22 \pm 15.36$ years, $193(49.00 \%)$ were males, and 292 $(67.30 \%)$ of the respondents had heard of the prospective COVID-19 vaccine. Among them, $232(79.50 \%)$ respondents had positive perception regarding COVID-19 vaccine. Individuals in the fifth wealth quintile were ten times more likely to be willing to pay for the prospective COVID-19 vaccine compared to those in the first wealth quintile [Adjusted Odds Ratio $=9.57,(95 \% \mathrm{Cl}=2.88-31.82), \mathbf{p}=<\mathbf{0 . 0 1}$ ]. CONCLUSION. The prospective COVID-19 vaccine should be subsidized or made freely available to everyone. 
1 The prospective COVID-19 vaccine: Willingness to pay and perception of community

2 members in Ibadan, Nigeria.

3

4 Olayinka Ilesanmi ${ }^{1,2}$, Aanuoluwapo Afolabi ${ }^{1 \&}$, Obioma Uchendu ${ }^{1,2}$

5

6 Authors' Affiliations

7 'Department of Community Medicine, University of Ibadan, Oyo state, Nigeria

$8{ }^{2}$ Department of Community Medicine, University College Hospital, Oyo state, Nigeria

9

10

11 \& corresponding author:

12 Aanuoluwapo Afolabi

13 Email: afoannade@gmail.com

14 Tel: +2348146764516

15

16

17

18

19

20

21

22

23

24 


\section{Abstract \\ BACKGROUND.}

The ongoing development of the COVID-19 vaccine necessitates the assessment of individual perception regarding the vaccine. This study aimed to assess the perception of community members and the willingness to pay for the prospective COVID-19 vaccine in Ibadan, Nigeria.

\section{METHODS.}

A descriptive cross-sectional study design was used. Data were collected using an intervieweradministered questionnaire in September 2020. We studied community members aged 15 years and above who provided verbal informed consent using a multi-stage sampling technique. The perceptions of respondents about COVID-19 were assessed on 8 questions using the five-point Likert scale with a score point of "1" assigned for "Strongly Agree", "2" for Agree", “3” for "Not decided", "4” for "Disagree”, and "5" for "Strongly disagree". During analysis, we reverse-coded the options by assigning a point of "1" for "Strongly disagree", "2" for "Disagree", "3" for "Not decided", "4" for "Agree", and "5" for "Strongly disagree". However, questions asked in the negative directions were not reverse-coded during analysis. Eight questions were used to assess the perception of community members regarding the prospective COVID-19 vaccine, and overall, the maximum point was 40 . Points greater than or equal to $\geq 32$ points $(80 \%)$ implied a positive perception. Descriptive statistics were done. Chi-square tests were used for the assessment of associations between sociodemographic characteristics and the willingness to pay for the prospective COVID-19 vaccine. We conducted logistic regression tests on statistically significant variables at $\mathrm{p}$-values $<0.05$.

\section{RESULTS.}

The mean age of the 440 respondents studied was $37.22 \pm 15.36$ years, $193(49.00 \%)$ were males, and 292 $(67.30 \%)$ of the respondents had heard of the prospective COVID-19 vaccine. Among them, 232 (79.50\%) respondents had positive perception regarding the COVID-19 vaccine. Individuals in the fifth wealth quintile were ten times more likely to be willing to pay for the prospective COVID-19 vaccine compared to those in the first wealth quintile [Adjusted Odds Ratio $=9.57,(95 \% \mathrm{CI}=2.88-31.82)$, $\mathbf{p}=<\mathbf{0 . 0 1}]$.

\section{CONCLUSION.}

The prospective COVID-19 vaccine should be subsidized or made freely available to everyone. 
INTRODUCTION

57

The 2019-Coronavirus disease (COVID-19) is a droplet infection characterized by rapid transmission, high mortality rate, and resulting complications among humans globally (AlHanawi et al., 2020). Due to these features, COVID-19 was declared a global pandemic by the World Health Organization (WHO), and thus necessitated the implementation of nonpharmaceutical control measures by all countries around the globe (WHO, 2020). These control measures have included the use of face masks, social distancing, school lockdowns, border closure, and hygiene protocols (Ilesanmi et al., 2020a; 2020b; NCDC, 2020a). In spite of the above-mentioned containment and control efforts, COVID-19 has remained a global threat with $100,383,705$ cases and 2,152,357 deaths recorded as of $25^{\text {th }}$ January, 2021 of which the African continent makes up 3.5\% of cases and 4\% mortality. Of this global total, Nigerian has reported 122,996 cases and 1,507 deaths as of the reference date (Worldometer, 2020). The daily rise in COVID-19-related cases and fatalities thus indicate the inadequacy of the present COVID-19 mitigation measures. This therefore reveals the need for the development of vaccines for the aversion of further spread of COVID-19 locally and globally, a task for which individual perception needs to be considered.

Vaccines have demonstrated an excellent historical capacity for the elimination of many infectious illnesses such as tetanus, diphtheria, polio, rabies, pertussis, measles, and yellow fever (Chukuocha et al., 2020). The routine immunization program and the expanded program on immunization have enabled the number of persons covered for immunization (Chukwuocha et al., 2020). These programs have represented great feats in the prevention of common childhood illnesses and the maintenance of the well-being of children. In the context of malarial infection, the development of an efficacious malarial vaccine has been suggested as a vital strategy for reducing the burden of malaria especially in malarial-endemic countries such as Nigeria and Ghana (Ojakaa et al., 2011). The RTS,S malaria vaccine has been developed, and is being researched for appropriate technology to evaluate its efficacy (Ojakaa et al., 2011). The development of a safe and effective vaccine against the Ebolavirus disease (EVD) has been identified as an important tool for the prevention of future EVD outbreaks (Ojakaa et al., 2011; Huo et al., 2016). In lieu of this, experimental vaccines on EVD have commenced in five 
85 districts in Sierra Leone where majority of EVD cases have been recorded. Vaccine development 86 however introduces new interventions. These may however be met with some challenges (Huo et 87 al., 2016).

88 Challenges have been experienced following the introduction of new health interventions in some settings. For instance, a polio vaccination program was rejected in a community in northern Nigeria due to wrong perception of religious leaders therein (Jegede, 2007). A similar experience was recorded in Ghana where community members rejected a mass deworming program scheduled by the government (Dodoo et al., 2007). In both instances, misunderstanding of the programs was responsible for their unsuccessful implementation (Febir et al, 2013). It is therefore evident that perception shapes one's knowledge of an infection and the acceptance of vaccination for its prevention. The Health Belief Model also posits that high levels of perceived susceptibility to an infection increases the likelihood for adopting and accepting of diseasepreventive measures (Tarkang \& Zotor, 2015). This array of evidence therefore indicates the need for evaluating the perception and practices of individuals prior to the introduction of a health intervention for each illness.

The uptake of vaccines and treatment options for illnesses have been described as an outplay of the cost evaluation in such regard among community members (Hajizadeh, 2018). Direct costs defined as the exact cost borne for the procurement of vaccines could be borne by a third party e.g. the government to improve the uptake of vaccines (Chukwuocha et al., 2018); however, the uptake of vaccines may remain yet unsatisfactory. Unsatisfactory levels of vaccine uptake could result from the indirect costs attached to receiving such vaccines. Indirect costs such as transportation expenses to the health facility, loss of productive hours during vaccination waiting time, and registration bills at health facilities could deter the acceptance of vaccination programs to reasonable levels (Hajizadeh, 2018). In the COVID-19 context, indirect costs could limit the prospective vaccine uptake despite the direct costs being borne by a sponsoring body. Although associated costs cannot be completely borne, the COVID-19 vaccine sponsoring body would need to ensure the decentralization of vaccine collection points to existing primary health centers available in community settings.

113 Given the novelty of COVID-19, its associated fatality, and ongoing efforts for the development of an effective COVID-19 vaccine, it therefore becomes needful to examine the knowledge, 
115 attitudes, and practices of community members in this regard. Findings from this study would be

116 helpful for the adequate planning for the introduction of effective COVID-19 vaccine. This

117 formative study would thus be important in quickening prompt interventions which would be

118 targeted at stimulating the right kind of support at community levels. This study therefore aimed

119 to assess the willingness to pay and perception of community members in Oyo State, Nigeria

120 regarding the COVID-19 vaccine.

121 MATERIALS AND METHODS

122 Study design and study setting

123 We conducted a descriptive cross-sectional study. Data was collected using an interviewer-

124 administered questionnaire. Scheduled data collection took place between the $21^{\text {st }}$ and $25^{\text {th }}$ of

125 September, 2020. We conducted the study in Ibadan, Oyo State, Nigeria. Ibadan is the third most

126 populated city, and the largest city by geographical area in Nigeria. Ibadan is located 128

127 kilometres inland northeast of Lagos and 530 kilometres southwest of Abuja, the Federal Capital

128 Territory. As of $31^{\text {st }}$ December, 2020, Oyo State ranked fiftth on the states affected by COVID-

12919 with 3,939 COVID-19 cases and 46 deaths recorded on the NCDC COVID-19 reports

130 (NCDC, 2020b). The lingua franca in Nigeria is English Language, and the major informal

131 language frequently used for communication in Ibadan is Yoruba.

\section{Study population}

133 All community members aged 15 years and above from the selected communities in Ibadan were

134 eligible to participate in the study. All individuals who provided verbal informed consent were

135 included in the study. Community members less than 15 years were excluded because parental

136 consent which would be required may not be possible due to parental absence when data

137 collection was ongoing. We obtained verbal consent from all study participants.

\section{Sample size determination and sampling technique}

139 We calculated the sample size using the formula for descriptive cross-sectional studies. The

140 sample size was determined by the Leshlie Kish formula for sample determination for a single

141 proportion as shown below:

$142 \mathrm{n}=\mathrm{Z}_{\alpha}^{2} * \mathrm{p}(1-\mathrm{p}) / \mathrm{d}^{2}$ where: 
$143 \mathrm{n}=$ Minimum desired sample size

$144 \mathrm{Z}_{\alpha}=$ the standard normal deviate, usually set as 1.96 which corresponds to a $5 \%$ level of

145 significance.

$146 \mathrm{p}=50 \%$ was used

$147 \mathrm{~d}=$ Degree of accuracy (precision) set at 5\% $(0.05)$

148 We adjusted for a 10\% non-response rate, and therefore generated a total sample size of 440

149 respondents.

150 We selected study respondents using a multi-stage sampling technique. In the stage 1, simple

151 random sampling was used to select 4 out of the 5 urban local government areas in Ibadan. The

152 choice of urban LGAs was preempted by the knowledge that many COVID-19 hotspots in

153 Ibadan are located in the urban LGAs. In the stage 2, we selected a political ward from each of

154 the selected LGAs. From each of the selected wards, we randomly chose a center location. The

155 direction of movement of the interviewers was determined by spinning a bottle. From areas

156 corresponding to the direction of the bottle tip, all eligible adults who gave verbal informed

157 consent were included in the study until 110 persons were interviewed in each LGA. Therefore,

158 we sampled a total of 440 individuals across the communities in the selected wards.

159 Data collection methods

160 The questionnaire had six sections.

161 Section A, named "Sociodemographic characteristics" included respondents' information such as

162 age of respondents, sex, occupation, religion, highest level of education, ethnicity, marital status,

163 average monthly income, and wealth quintile. The second section named "Knowledge of

164 COVID-19" was used to elicit information on the knowledge of COVID-19 among community

165 members. The third section, "Knowledge of the prospective COVID-19 vaccine" provided

166 details on the knowledge of community members regarding the prospective COVID-19 vaccine.

167 Close-ended questions were asked on the knowledge of COVID-19 as well as the awareness of 168 the prospective COVID-19 vaccine. 
169 The fourth section, named "Perceptions about the prospective COVID-19 vaccine" elicited

170 information on the perceptions of community members regarding the prospective COVID-19

171 vaccine. Eight questions were asked on the perception about COVID-19 vaccine using a five-

172 point Likert scale ranging from "Strongly Agree" to "Strongly Disagree". The questions asked

173 are as follows: "COVID-19 is a major public health problem requiring vaccine", "COVID-19

174 vaccine will prevent COVID-19”, “COVID-19 vaccine should get administered to everyone”,

175 “COVID-19 vaccine is against our cultural belief”, "COVID-19 vaccine will save productive

176 hours lost to COVID-19 illness", "COVID-19 vaccine will save money spent on COVID-19

177 treatment", "I will take the COVID-19 vaccine when produced", and the "COVID-19 vaccine

178 will not have adverse health effect". The fifth section, "Willingness to pay for the prospective

179 COVID-19 vaccine" examined the willingness of community members regarding payment for

180 the prospective COVID-19 vaccine. Close-ended questions were asked on the willingness to pay

181 for the COVID-19 vaccine and the intent to comply with the prospective COVID-19 vaccine.

182 The questions included "Are you willing to pay for the COVID-19 vaccine?", "If yes, specify

183 reasons for your willingness", "If no, specify reasons for your unwillingness", and "What

184 maximum amount are you willing to pay for the vaccine?". The interviewer correctly marked all

185 points stated by the respondents. The sixth section, "Information required before accepting the

186 prospective COVID-19 vaccine" provided details on the information community members

187 required before willingness to accept the COVID-19 vaccine could be gained.

188 We adapted the questionnaire from a tool used in a similar perception study on malarial vaccine

189 in Southeast Nigeria (Chukuocha et al., 2018). Tool validation was done by an infectious disease

190 epidemiologist. The questionnaire was pre-tested by the administration of 5 questionnaires in

191 communities that were not selected for this study. We rephrased a few ambiguous questions. We

192 back-translated the questionnaire using the competencies of experts who had an excellent grasp

193 of the Yoruba language. We administered the questionnaire to most of the respondents in English

194 language because a larger proportion of the study respondents had at least basic formal

195 education. A postgraduate student was trained for data collection, and this helped to eliminate

196 potential bias associated with administration of questionnaire by more individuals.

197 Independent variables included: Sociodemographic characteristics such as age, sex, level of

198 education, occupation, and ethnic group. 
199 Outcome/dependent variables were the knowledge of the prospective COVID-19 vaccine,

200 perception regarding the prospective COVID-19 vaccine, the willingness to pay for the vaccine, 201 and information required before accepting the prospective COVID-19 vaccine.

\section{Data management}

203 The Statistical Program for Social Sciences (SPSS version 20) software was used to analyze data 204 after data entry and cleaning (IBM Corp, 2011). Age was summarized using mean and standard deviation, while frequencies and percentages were used for categorical variables. We assigned

206

207

208

209

210

211

212

213

214

215

216

217

218

219

220

221

222

223

224

225

226

227

228 points of " 1 " and " 0 " to each correct and incorrect identified cause of COVID-19 respectively for 5 questions on the causes of COVID-19. Using the Bloom's cut-off, individuals with 3 or more cumulative points were categorized to have good knowledge of the cause of COVID-19, while people with lower points therefore had poor knowledge of COVID-19 cause.

We calculated the wealth index of respondents using the Principal Components Analysis (PCA) in SPSS (IBM Corp, 2011). The input to the PCA included responses on ownership of house and other key assets such as a stove, electric fan, refrigerator, air conditioner, radio, television, and generator, piped water in the household, bicycle, motor vehicle, upholstered chairs, sewing machine and washing machine. Thereafter, we calculated distribution cut-off points using quintiles. The quintiles were Q1 = first, Q2=second, Q3=third, Q4= fourth, Q5=fifth; with the poorest in the first wealth quintile and the richest in the fifth wealth quintile.

Individuals who have heard of the prospective COVID-19 vaccine were assigned a score of "1", while those who have not heard were assigned a score of "0". Among the respondents who have heard of the prospective vaccine, the sources of COVID-19 vaccine information were assessed. The perceptions of respondents about COVID-19 were assessed using the five-point Likert scale with options ranging from "Strongly Agree" to "Strongly disagree". We assigned a score of "1" to the "Strongly Agree "option, "2" to the "Agree" option; "3" to the "Not decided" option, "4" to the "Disagree" option, and " 5 " to the "Strongly disagree" option. At the point of data analysis, recoding of the five-point Likert scale was done for questions which had been asked in the positive direction. Therefore, we computed a score of "5" for the "Strongly Agree" option, "4" for "Agree", "3" for "Not decided", "2" for "Disagree", and "1" for the "Strongly disagree" option. Eight questions were asked on the perception of community members regarding the prospective COVID-19 vaccine for which a total of " 40 " points were obtainable. Using the 
229 Bloom's cut-off point, scores $\geq 32$ points $(\geq 80 \%)$ implied a positive perception, while those

230 corresponding to $<32$ points $(<80 \%)$ implied a negative perception regarding the prospective

231 COVID-19 vaccine.

232 Chi-square tests were used for the assessment of associations between sociodemographic 233 characteristics and the willingness to pay for the prospective COVID-19 vaccine. Multivariate 234 analysis of the determinants of willingness to pay for the prospective COVID-19 vaccine was 235 conducted using the Logistic regression model. Since no data was collected at stages 1 and 2 of 236 the sampling process, we built logistic regression without adjusting for clustering. P-values $237<0.05$ were statistically significant.

\section{Ethical approval and consent to participate}

240

241

242

243

244

245

246

247

248

249

250

251

252

253

254

255

256

We obtained ethical approval for this study as part of COVID-19 Knowledge, attitude, practice and perception studies from the Oyo State Ministry of Health Ethical Review Committee with reference number $\mathrm{AD} / 13 / 479 / 1779 \mathrm{~A}$. Informed consent and/or assent where required was obtained from the respondents. All respondents were assured of the confidentiality of information obtained from them. The respondents were duly informed of their right to withdraw from the study prior to its completion without any adverse implication. No known harm was inflicted on the respondents as a result of participation in this study.

\section{RESULTS}

The mean age of the 440 respondents was $37.22 \pm 15.36$ years. Overall, $202(45.90 \%)$ were aged between 21 and 40 years. Among the respondents, 193 (43.90\%) were males, 293 (66.60\%) practiced Christianity, 371 (84.3\%) were Yoruba, and 285 (64.80\%) were married. Other sociodemographic information is as shown in Table 1.

Among the respondents, 311 (70.70\%) had good knowledge of the cause of COVID-19. The causes of COVID-19 stated included contacts with saliva from a COVID-19-infected person and participating in burial rites of a person who has died from COVID-19. Other causes mentioned by respondents included contact with beddings, clothing, and personal utensils of a person who is 
257 sick of COVID-19, and respiratory droplets of an infected person. Also, $292(67.30 \%)$ of the

258 respondents had heard of the prospective COVID-19 vaccine. Among them, 205 (70.20\%) had

259 gotten the prospective COVID-19 vaccine information from the radio, while $201(68.80 \%)$ had

260 been informed on the prospective COVID-19 vaccine via the television. Also, 175 (59.90\%)

261 respondents were informed of the COVID-19 vaccine through the social media. Other sources of

262 information on the prospective COVID-19 vaccine are as shown in Figure 1.

263 Table 2 shows the perceptions on the prospective COVID-19 vaccine among respondents.

264 Among the respondents, 281 (96.20\%) strongly agreed that COVID-19 is a major public health

265 problem requiring vaccine, while 279 (95.50\%) strongly agreed that the COVID19 vaccine

266 would prevent COVID-19. Also, 182 (62.30\%) strongly disagreed that the COVID-19 vaccine is

267 against their cultural belief, and 180 (61.60\%) strongly agreed to take the COVID-19 vaccine

268 when produced.

269 Overall, 232 (79.50\%) respondents had a positive perception regarding COVID-19 vaccine 270 compared to $60(20.50 \%)$ with negative perception. Eighty-one (18.40\%) of the respondents

271 were willing to pay for the prospective COVID-19 vaccine, among whom 45 (55.6\%) were

272 willing to pay at least 5000 naira $(\$ 13.16)$. All $81(100.00 \%)$ respondents who were willing to

273 pay for the COVID-19 vaccine attributed their willingness to the need to stay healthy. All 359

$274(100.00 \%)$ respondents who were unwilling to pay for the vaccine attributed their unwillingness

275 to the unaffordability of vaccine costs by households. Also, 275 (62.50\%) respondents require

276 specific information on the prospective COVID-19 vaccine before accepting it (Table 3).

277 Fourteen (15.90\%) respondents who belonged to the fourth wealth quintile were willing to pay

278 for the prospective COVID-19 vaccine compared to $74(84.10 \%)$ within same wealth quintile

279 who were unwilling to pay. Forty-eight (54.50\%) respondents in the fifth wealth quintile were

280 willing to pay for the prospective COVID-19 vaccine compared to 40(45.50\%) who were

281 unwilling to pay $\left(X^{2}=99.32, \mathbf{p}=<\mathbf{0 . 0 1}\right)$. Individuals in the fourth wealth quintile were twice more

282 likely to be willing to pay for the COVID-19 vaccine compared to those in the first wealth

283 quintile [Adjusted Odds Ratio $=2.22,95 \% \mathrm{CI}=0.66-7.44), \mathrm{p}=0.20$ ). Individuals in the fifth wealth

284 quintile were ten times more likely to be willing to pay for the prospective COVID-19 vaccine

285 compared to those in the first wealth quintile [Adjusted Odds Ratio=9.57, $(95 \% \mathrm{CI}=2.88-31.82)$, 
$286 \mathrm{p}=<\mathbf{0 . 0 1}]$. Other determinants of the willingness to pay for the COVID-19 vaccine are as shown

287 in Table 4.

\section{DISCUSSION}

289 This study found that a large proportion of individuals (100.00\%) were aware of the COVID-19

290 infection. Such a level of awareness is expected because COVID-19 occurrence is not a

291 completely new event in Nigeria. Nigeria has been faced with the COVID-19 pandemic since the

$29227^{\text {th }}$ of February, 2020, and implemented some mitigation measures regarding the containment of

293 the COVID-19 infection. In this study, we found that many individuals $(67.30 \%)$ are aware of

294 the prospective COVID-19 vaccine. This finding could be possibly explained by the higher

295 proportion of individuals with secondary education and above enrolled in this study. Some

296 literatures have also reported the positive relationship between education and health awareness

297 (Sani et al., 2016; Wang et al., 2018). Education may therefore be an important predictor of the

298 awareness of prospective health interventions in communities with more educated persons.

299 However, alternate channels of information could be employed in communicating intended

300 health interventions across all educational levels in communities.

301 Regarding the source of information on the prospective COVID-19 vaccine, traditional media

302 such as the radio and television provided more information to more individuals compared to

303 other channels of information dissemination. Other studies have reported the dominance of

304 traditional media in communicating COVID-19-related information (Olapegba et al., 2020;

305 Ilesanmi \& Afolabi, 2020a). The social media, a modern channel of information source, also

306 accounted for nearly two-thirds of COVID-19 vaccine information. Findings from Egypt

307 however reported that Facebook, a modern information site mainly provided information on

308 COVID-19 to her citizens (Abdelhafiz et al., 2020). In addition, the internet, a social media

309 platform, provided more Undergraduate students in Jordan with information on COVID-19

310 (Olaimat et al., 2020). This finding therefore highlights the need for harnessing these channels of

311 information dissemination with high coverage to communicate rich information on the COVID-

31219 vaccine. Due to the aforementioned reasons, the Nigeria Center for Disease Control utilizes

313 both the traditional and social media platforms for communicating COVID-19 information

314 (Adepoju, 2020; Sote, 2020). In the COVID-19 vaccine context, it is required that collaboration

315 be implemented across these platforms for the timely dissemination of information to members 
316 of the public. Health facilities should also be equipped with up-to-date information on the

317 prospective COVID-19 vaccine for dissemination to individuals on hospital visits.

318 We found that many individuals acknowledged that COVID-19 is a public health problem

319 requiring vaccine, and were confident that the COVID-19 vaccine will prevent COVID-19. The

320 demonstration of such levels of assurance could be described as an outplay of the positive results

321 gained from previous vaccination programs such as oral polio vaccination (OPV), measles, and

322 yellow fever (Doherty et al., 2016). These vaccination programs led to a drastic reduction in the

323 incidence of these illness, and helped to maintain healthy conditions in children (Febir et al.,

324 2013; Chukwuocha et al., 2018). Many respondents strongly agreed that the COVID-19 vaccine

325 will save productive hours and money lost to the COVID-19 illness. Loss of productive hours in

326 the COVID-19 context has been reported to include the turn-out time for collection of COVID-

32719 test results, and time spent on isolation (Ilesanmi and Afolabi, 2020b; 2020c). In spite of these

328 potential benefits presented by the prospective COVID-19 vaccine, fewer persons however

329 expressed their willingness to take the COVID-19 vaccine. Such unwillingness for vaccine

330 acceptance stemmed from the skepticism associated with the affordability of the COVID-19

331 vaccine by households if costs were involved.

332 The minimum monthly wage of 30, 000 naira (\$78.95) received by many Nigerians is an

333 evidence that if COVID-19 vaccine costs exceeds 5,000 naira (\$13.16), such procurement may

334 not be affordable to the average Nigerian. Non-compliance to health interventions especially in

335 low-resourced settings have been linked to the costs and affordability of such interventions. This

336 has therefore limited the successes achieved on priority illnesses, such as malaria (Chukwuocha

337 et al., 2018). Health interventions with no attached healthcare costs have achieved better results

338 (Chukwuocha et al., 2018). Affordability by households should therefore be one of the factors

339 given precedence during the planning and implementation of the prospective COVID-19 vaccine

340 production. In addition, consideration should be given to all income groups in the population so

341 that no population subgroup would be excluded from partaking of the prospective COVID-19

342 vaccine program.

343 Among the respondents who would require specific information on the prospective COVID-19

344 vaccine, information on payments was the most frequently stated required information. This

345 posits that the costs attached could either reduce or increase the uptake of the COVD-19 vaccine 
346 when produced. Many individuals would also require information on the possible side effects

347 before accepting the COVID-19 vaccine. Although it is known that many existing vaccines have 348 minimal levels of side effects such as temporary diarrhea (CDC, 2020), the novelty of the 349 prospective COVID-19 vaccine necessitates specific information on its side effects. If the 350 possible side effects of the prospective COVID-19 vaccine are not too different from the side 351 effects experienced with other illnesses for which vaccines are received, more individuals are 352 likely to accept the prospective COVID-19 vaccine. Studies conducted on malarial vaccine have 353 similarly documented side effects as an inevitable factor which influences the acceptance and 354 compliance with the malarial vaccine (Menaca et al., 2014; Abdulkadir et al., 2015). The side 355 effects of the prospective COVID-19 vaccine (if any) should be communicated alongside 356 COVID-19 mitigation measures on the radio, tv, internet sites, and health facilities to ensure that 357 no one is excluded regarding the COVID-19 vaccine information.

358 This study found that occupation is an important determinant to the willingness to pay for the 359 COVID-19 vaccine. We similarly found that wealth index also determines the willingness to pay 360 for the COVID-19 vaccine. This finding therefore implies that individuals in the higher wealth

361

362

363

364

365

366

367

368

369

370

371

372

373

374

375 quintile are willing to pay for the prospective COVID-19 vaccine primarily because they could afford it. Building on the foregoing, persons in the lower wealth quintile would be missed out on in the implementation of the prospective COVID-19 vaccine if only the higher wealth quintiles are considered regarding affordability of the COVID-19 vaccine. Previous studies conducted on malarial vaccine did not report any association between occupation or wealth index and willingness to pay for the vaccine (Menaca et al., 2014; Abdulkadir et al., 2015). In view of the present study, the COVID-19 pandemic has greatly affected the income of many individuals, and this could be an explanation for this finding. This finding further posits the need for the subsidization of the COVID-19 vaccine to improve the uptake of the vaccine when available.

\section{Strengths of the Study}

Up-to-date, majority of COVID-19 researches have been conducted on the knowledge, attitude, and practices of population groups on the COVID-19 illness itself. In line with recent developments on the containment and prevention of the COVID-19 infection, the present study has gone a step further in assessing the perception and willingness to pay for the prospective COVID-19 vaccine. To the best of our knowledge, this is the first of its kind. We also ruled out 
376 bias associated with multiple data collectors or the use of electronic data collection tools by

377 using only one interviewer for data collection.

\section{Limitations of the Study}

380 Firstly, the study respondents were largely literate. The findings from this study therefore may

381

382

383

384

385

386

387

388

389

390

391

392

393

394

395

396

397 398

399

400

401

402 not be generalizable in a less-literate setting. Also, the use of a small sample size limited the results obtained during further analysis, resulting in an extremely large confidence interval.

\section{Conclusion}

The perception of the prospective COVID-19 vaccine determines the willingness to take the COVID-19 vaccine. It also influences the compliance of an individual with the prospective COVID-19 vaccine. Individuals may be willing to take the COVID-19 vaccine, however the cost of purchasing it may not be affordable. It is therefore required that the prospective COVID-19 vaccine is fully subsidized or freely given in order to encourage its uptake among all individuals. In addition, information on the prospective COVID-19 vaccine and possible adverse effects should be adequately communicated in clear terms through different channels of information such as tv and radio stations, social media, and health facilities. This will aid the implementation, acceptance, and compliance to the prospective COVID-19 vaccine, and will aid the sustainable journey towards the elimination of the COVID-19 pandemic. Further research should be conducted across COVID-19 affected countries to assess the preparedness of community members towards the eventual roll-out of the prospective COVID-19 vaccine.

\section{ACKNOWLEDGEMENTS}

The authors are grateful to all the community members who participated in this research. 
403

404

405

406

407

408

409

410

411

412

413

414

415

416

417

418

419

420

421

422

423

424

425

426

427

428

429

\section{References}

Abdulkadir BI, Ajayi IO. 2015. Willingness to accept malaria vaccine among caregivers of under-5 children in Ibadan North Local Government Area, Nigeria. MalariaWorld Journal 6:2.

Adepoju P. 2020. Nigeria responds to COVID-19; first case detected in sub-Saharan Africa. Nature Medicine 26(4). doi: 10.1038/d41591-020-00004-2.

CDC. 2018. Vaccines and preventable diseases. Available at https://www.cdc.gov/vaccines/vpd/rotavirus/public/index.html. (Accessed 02 October, 2020).

Chukwuocha M, Okorie PC, Iwuoha GN, Ibe SN, Dozie IN. 2018. Awareness, perceptions and intent to comply with the prospective malaria vaccine in parts of South Eastern Nigeria. BMC Malaria Journal 17:187. doi: 10.1186/s12936-018-2335-0.

Dodoo A, Adjei S, Couper M, Hugman B, Edwards R. 2007. When rumors derail a mass deworming exercise. Lancet 370:465-466. doi: 10.1016/S0140-6736(07)61211-2.

Doherty M, Buchy P, Standaert B, Giaquinto C, Prado-Cohrs D. 2020. Vaccine impact: benefits for human health. Vaccine 34(52):6707-6714. doi: 10.1016/j.vaccine.2016.10.025.

Febir LG, Asante KP, Dzorgbo D-B S, Senal KA, Letsa TS, Owusu-Agyei S. 2013. Community perceptions of a malaria vaccine in the Kintampo districts of Ghana. Malaria Journal 12:156. doi: 10.1186/1475-2875-11-394.

Hajizadeh M. 2018. Socioeconomic inequalities in child vaccination in low/middle-income countries: what accounts for the differences? Journal of Epidemiology and Community Health 72:719-725. doi:10.1136/jech-2017-210296.

Huo X, Shi G, Li X, Lai X, Deng L, Xu F, Chen M, Wei Q, Samba T, Liang X. 2016. Knowledge and attitudes about Ebola vaccine among the general population in Sierra Leone. Vaccine 34(15):1767-1772. doi:10.1016/j.vaccine.2016.02.046.

IBM Corp. 2011. IBM SPSS Statistics for Windows, Version 20.0. Armonk, NY: IBM Corp. Ilesanmi OS, Afolabi AA. 2020a. Perception and practices during the COVID-19 pandemic in an urban community in Nigeria: a cross-sectional study. Peer Journal 8:e10038. doi: $10.7717 /$ peerj.10038. 
430 Ilesanmi OS, Afolabi AA. 2020b. In search of the true prevalence of COVID-19 in Africa: Time 431 to involve more stakeholders. International Journal of Health and Life Sciences In Press(In 432 Press):e108105. doi: 10.5812/ijhls.108105.

433 Ilesanmi OS, Afolabi AA. 2020c. Time to move from vertical to horizontal approach in our 434 COVID-19 response in Nigeria. SciMedicine Journal 3(Special):198-200.

435 Ilesanmi OS, Oguntoye AA, Afolabi AA. 2020a. The new norm in the management of COVID43619 positives: Home-based care. Journal of Ideas in Health 3(4):252-253.

437 Ilesanmi OS, Ariyo M, Afolabi AA. 2020b. Domestic violence amid the COVID-19 lockdown: 438 a threat to individual safety. Global Biosecurity 2(1).

439 Jegede AS. 2007. What led to the Nigerian boycott of the polio vaccination campaign? PLoS 440 Medicine 4:e73. doi: 10.1371/journal.pmed.0040073. doi: 10.28991/SciMedJ-2020-02-SI-3.

441 Menaca A, Tagbor H, Adjei R, Bart-Plange C, Collymore Y, Ba-Nguz A, Mertes K, Bingham A. 442 2014. Factors likely to affect community acceptance of a malaria vaccine in two districts of 443 Ghana: a qualitative study. PLoS ONE. 2014;9:e109707. doi:10.1371/journal.pone.0109707.

444 NCDC. 2020. COVID-19 Nigeria. Nigeria Centre for Disease Control. Available at 445 https://covid19.ncdc.gov.ng/. (accessed 01 December 2020).

446 NCDC. 2020. COVID-19 Nigeria. Nigeria Centre for Disease Control. Available at 447 https://covid19.ncdc.gov.ng/. (accessed 02 December 2020).

448 Ojakaa DI, Ofware P, Machira YW, Yamo E, Collymore Y, Ba-Nguz A, Vansadia P, Bingham 449 A. 2011. Community perceptions of malaria and vaccines in the South Coast and Busia regions 450 of Kenya. Malaria Journal 10:147. doi: 10.1186/1475-2875-10-147.

451 Olaimat AN, Aolymat I, Shahbaz HM, Holley RA. 2020. Knowledge and Information Sources 452 About COVID-19 Among University Students in Jordan: A Cross-Sectional Study. Frontiers in 453 Public Health 8: 254. doi: 10.3389/fpubh.2020.00254. eCollection 2020.

454 Sani AM, Naab F, Aziato L. 2016. Influence of educational level on knowledge and practice of 455 breast self-examination among women in Sokoto, Nigeria. Journal of Basic and Clinical 456 Reproductive Sciences 5(2):100-106. doi: 10.4103/2278-960X.194482. 
457 Sote L. 2020. So that Coronavirus won't consume us. The Punch Newspaper. Available at 458 https://punchng.com/so-that-coronavirus-wont-consume-us/. (accessed 20 June 2020).

459 Tarkang EE, Zotor FB. 2015. Application of the Health Belief Model (HBM) in HIV Prevention:

460 A Literature Review. Central African Journal of Public Health 1: 1-8.

461 doi: 10.11648/j.cajph.20150101.11

462 Wang M, Han X, Fang H, Xu C, Lin X, Xia S, Yu W, He J, Jiang S, Tao H. 2018. Impact of

463 Health education on knowledge and behaviors towards infectious diseases among students in

464 Gansu Province, China. BioMed Research International.2018;1-12. doi: 10.1155/2018/6397340.

465 WHO. 2020. Coronavirus disease 2019 (COVID-19) Situation Report -51 Geneva: World

466 Health Organization. Available at https://covid19.who.int/. (Accessed 19 September 2020).

467 Worldometer. 2020. COVID-19 Coronavirus Pandemic. Available at

468 https://www.worldometers.info/coronavirus/. (Accessed 26 January 2021).

469

470

471

472

473

474

475

476

477

478

479

480

481

Peer] reviewing PDF | (2020:10:53473:4:0:NEW 26 Jan 2021) 


\section{Table 1: Socio-demographic characteristics of community members in Ibadan, Nigeria}

\begin{tabular}{|c|c|c|c|c|}
\hline \multirow{2}{*}{$\begin{array}{l}\text { Socio-demographic Characteristics } \\
\text { Age group (Years) }\end{array}$} & \multirow[t]{2}{*}{ Frequency } & \multirow[t]{2}{*}{$\%$} & \multicolumn{2}{|c|}{ 95\% Confidence Interval } \\
\hline & & & Upper & Lower \\
\hline$\leq 20$ & 68 & 15.50 & 12.40 & 19.10 \\
\hline $21-40$ & 202 & 45.90 & 41.30 & 50.60 \\
\hline $41-60$ & 131 & 29.80 & 25.70 & 34.20 \\
\hline$>60$ & 39 & 8.90 & 6.60 & 11.90 \\
\hline \multicolumn{5}{|l|}{ Sex } \\
\hline Male & 193 & 43.90 & 39.30 & 48.50 \\
\hline Female & 247 & 56.10 & 51.50 & 60.70 \\
\hline \multicolumn{5}{|l|}{ Religion } \\
\hline Christianity & 293 & 66.60 & 61.40 & 70.20 \\
\hline Islam & 145 & 33.00 & 28.70 & 37.50 \\
\hline Traditional & 2 & 0.50 & 0.12 & 1.64 \\
\hline \multicolumn{5}{|l|}{ Highest level of Education } \\
\hline Primary and below & 64 & 14.50 & 11.60 & 18.10 \\
\hline Secondary and above & 376 & 85.50 & 81.90 & 88.40 \\
\hline \multicolumn{5}{|l|}{ Ethnicity } \\
\hline Yoruba & 371 & 84.30 & 80.60 & 87.40 \\
\hline Ibo & 59 & 13.40 & 10.50 & 16.90 \\
\hline Hausa & 10 & 2.30 & 1.20 & 4.10 \\
\hline \multicolumn{5}{|l|}{ Occupation } \\
\hline Business/Trader & 162 & 36.80 & 32.40 & 41.40 \\
\hline Artisan & 101 & 23.00 & 19.27 & 27.11 \\
\hline Professional/Civil Servant/Teacher & 68 & 15.50 & 12.38 & 19.13 \\
\hline Retiree/housewife/cleric/student & 109 & 24.80 & 20.97 & 29.01 \\
\hline \multicolumn{5}{|l|}{ Marital Status } \\
\hline Married & 285 & 64.80 & 60.20 & 69.10 \\
\hline Single & 132 & 30.00 & 25.91 & 34.44 \\
\hline Others* & 23 & 5.20 & 3.51 & 7.72 \\
\hline \multicolumn{5}{|l|}{ Average monthly income } \\
\hline$<30,000$ naira & 149 & 33.90 & 29.60 & 38.41 \\
\hline$\geq 30,000$ naira & 291 & 66.10 & 61.59 & 70.40 \\
\hline \multicolumn{5}{|l|}{ Wealth quintiles } \\
\hline First & 88 & 20.00 & 16.53 & 23.99 \\
\hline Second & 88 & 20.00 & 16.53 & 23.99 \\
\hline Third & 88 & 20.00 & 16.53 & 23.99 \\
\hline Fourth & 88 & 20.00 & 16.53 & 23.99 \\
\hline Fifth & 88 & 20.00 & 16.53 & 23.99 \\
\hline
\end{tabular}

$483 *$ *: Widowed/divorced 


\section{Table 2: Perceptions on the prospective COVID-19 vaccine among community members in} 486 Ibadan, Nigeria

\begin{tabular}{|c|c|c|c|c|}
\hline \multirow[t]{2}{*}{ Perception } & \multirow[t]{2}{*}{ Frequency } & \multirow[t]{2}{*}{$\%$} & \multicolumn{2}{|c|}{$\mathbf{9 5 \%}$ Confidence Interval } \\
\hline & & & Upper & Lower \\
\hline \multicolumn{5}{|c|}{$\begin{array}{l}\text { COVID-19 is a major public health problem requiring } \\
\text { vaccine (Total }=292 \text { ) }\end{array}$} \\
\hline Strongly Agreed & 281 & 96.20 & 93.38 & 97.88 \\
\hline Agreed & 2 & 0.70 & 0.19 & 2.46 \\
\hline Not decided & 3 & 1.00 & 0.35 & 2.98 \\
\hline Disagree & - & - & - & - \\
\hline Strongly disagreed & 6 & 2.10 & 0.95 & 4.41 \\
\hline \multicolumn{5}{|c|}{ COVID-19 vaccine will prevent COVID-19 $($ Total $=292)$} \\
\hline Strongly Agreed & 279 & 95.50 & 92.53 & 97.38 \\
\hline Agreed & 3 & 1.00 & 0.35 & 2.98 \\
\hline Not decided & 4 & 1.40 & 0.53 & 3.47 \\
\hline Disagree & - & - & - & - \\
\hline Strongly disagreed & 6 & 2.10 & 0.95 & 4.41 \\
\hline \multicolumn{5}{|c|}{$\begin{array}{l}\text { COVID-19 vaccine should get administered to everyone } \\
(\text { Total }=292)\end{array}$} \\
\hline Strongly Agreed & 209 & 71.60 & 66.15 & 76.44 \\
\hline Agreed & - & - & - & - \\
\hline Not decide & 11 & 3.80 & 2.12 & 6.62 \\
\hline Disagree & 26 & 8.90 & 6.15 & 12.73 \\
\hline Strongly disagreed & 46 & 15.80 & 12.02 & 20.37 \\
\hline \multicolumn{5}{|c|}{$\begin{array}{l}\text { COVID-19 vaccine is against our cultural belief } \\
(\text { Total }=\mathbf{2 3 8})\end{array}$} \\
\hline Strongly Agreed & 31 & 10.60 & 9.33 & 17.90 \\
\hline Agreed & 35 & 12.00 & 10.77 & 19.77 \\
\hline Not decide & 44 & 15.10 & 14.07 & 23.91 \\
\hline Disagree & - & - & - & - \\
\hline Strongly disagreed & 182 & 62.30 & 70.69 & 81.41 \\
\hline \multicolumn{5}{|c|}{$\begin{array}{l}\text { COVID-19 vaccine will save productive hours lost to } \\
\text { COVID-19 illness }(\text { Total }=292)\end{array}$} \\
\hline Strongly Agreed & 270 & 92.50 & 88.86 & 94.97 \\
\hline Agreed & 4 & 1.40 & 0.53 & 3.47 \\
\hline
\end{tabular}




\begin{tabular}{|c|c|c|c|c|}
\hline Not decided & 13 & 4.50 & 2.62 & 7.47 \\
\hline Disagree & - & - & - & - \\
\hline Strongly disagreed & 5 & 1.70 & 0.73 & 3.95 \\
\hline \multicolumn{5}{|c|}{$\begin{array}{l}\text { COVID-19 vaccine will save money spent on COVID-19 } \\
\text { treatment (Total }=292)\end{array}$} \\
\hline Strongly Agreed & 272 & 93.20 & 89.66 & 95.52 \\
\hline Agreed & 3 & 1.00 & 0.35 & 2.98 \\
\hline Not decided & 12 & 4.10 & 2.37 & 7.04 \\
\hline Disagree & - & - & - & - \\
\hline Strongly disagreed & 5 & 1.70 & 0.73 & 3.95 \\
\hline \multicolumn{5}{|c|}{ I will take the vaccine when produced $($ Total $=292)$} \\
\hline Strongly Agreed & 180 & 61.60 & 55.95 & 67.04 \\
\hline Agreed & 4 & 1.40 & 0.53 & 3.47 \\
\hline Not decided & 76 & 26.00 & 21.33 & 31.35 \\
\hline Disagree & 9 & 3.10 & 1.63 & 5.75 \\
\hline Strongly disagreed & 23 & 7.90 & 5.31 & 11.54 \\
\hline \multicolumn{5}{|c|}{$\begin{array}{l}\text { COVID-19 vaccine will not have adverse health effects } \\
(\text { Total }=292)\end{array}$} \\
\hline Strongly Agreed & 133 & 45.50 & 39.93 & 51.28 \\
\hline Agreed & 3 & 1.00 & 0.35 & 2.98 \\
\hline Not decided & 147 & 50.30 & 44.64 & 56.04 \\
\hline Disagree & 2 & 0.70 & 0.19 & 2.46 \\
\hline Strongly disagreed & 7 & 2.40 & 1.17 & 4.86 \\
\hline
\end{tabular}

487

488

489

490

491

492

493

494

495

496 
497 Table 3: Willingness to pay for the COVID-19 vaccine and COVID-19 information

498 required by community members in Ibadan, Nigeria

\begin{tabular}{|c|c|c|c|c|}
\hline \multirow{2}{*}{ Willingness to pay for the COVID-19 vaccine } & \multirow[t]{2}{*}{$\mathbf{n}$} & \multirow[t]{2}{*}{$\%$} & \multicolumn{2}{|c|}{ 95\% Confidence Interval } \\
\hline & & & Upper & Lower \\
\hline Yes & 81 & 18.40 & 15.07 & 22.30 \\
\hline No & 359 & 81.60 & 77.70 & 84.93 \\
\hline \multicolumn{5}{|l|}{$\begin{array}{l}\text { Maximum amount intended for payment } \\
(\text { Total }=81)\end{array}$} \\
\hline$<5000$ naira $(\$ 13.16)$ & 36 & 44.40 & 34.12 & 55.27 \\
\hline$\geq 5000$ naira $(\$ 13.16)$ & 45 & 55.60 & 44.73 & 65.88 \\
\hline \multicolumn{5}{|l|}{ Reasons for willingness* } \\
\hline To stay healthy & 81 & 100.00 & 95.47 & 100.00 \\
\hline To prevent loss of productive hours & 23 & 28.40 & 19.73 & 39.02 \\
\hline To prevent further treatment expenses & 23 & 28.40 & 19.73 & 39.02 \\
\hline To promote social acceptability of vaccines & 9 & 11.10 & 5.96 & 19.79 \\
\hline \multicolumn{5}{|l|}{ Reasons for unwillingness* } \\
\hline Costs not affordable by households & 359 & 100.00 & 98.98 & 100.00 \\
\hline Fear of adverse effects & 30 & 8.40 & 5.92 & 11.68 \\
\hline Fear of inaccessibility of vaccines & 2 & 0.60 & 0.04 & 2.38 \\
\hline Contrary to religious beliefs & 16 & 4.50 & 2.76 & 7.12 \\
\hline Contrary to culture & 1 & 0.30 & 0.01 & 1.31 \\
\hline \multicolumn{5}{|l|}{ Require specific information on COVID-19 vaccine } \\
\hline Yes & 275 & 62.50 & 57.89 & 66.90 \\
\hline No & 165 & 37.50 & 33.10 & 42.11 \\
\hline \multicolumn{5}{|l|}{ Information required before accepting COVID-19 vaccine* } \\
\hline Whether payments would be required & 248 & 90.20 & 86.09 & 93.16 \\
\hline Possible side effects of the vaccine & 175 & 63.60 & 57.80 & 69.10 \\
\hline Number of doses needed & 131 & 47.60 & 41.81 & 53.53 \\
\hline Whether the vaccine will prevent or cure COVID-19 & 90 & 32.70 & 27.45 & 38.48 \\
\hline Route of administration & 58 & 21.10 & 16.68 & 26.29 \\
\hline Age range of individuals to be vaccinated & 53 & 19.30 & 15.05 & 24.35 \\
\hline Manufacturer of the vaccine & 24 & 8.70 & 5.93 & 12.66 \\
\hline Vaccine collection points & 17 & 6.20 & 3.90 & 9.68 \\
\hline Duration of immunity provided & 11 & 2.50 & 2.25 & 7.02 \\
\hline Whether vaccination would be accompanied by incentives & 7 & 2.70 & 1.24 & 5.16 \\
\hline Vaccine's expiry date & 2 & 0.50 & 0.20 & 2.61 \\
\hline
\end{tabular}









\section{Table 4: Association between sociodemographic characteristics and willingness to pay for}

\section{2 the prospective COVID-19 vaccine among community members in Ibadan, Nigeria}

\begin{tabular}{|c|c|c|c|c|}
\hline \multirow{2}{*}{$\begin{array}{l}\text { Socio-demographic } \\
\text { Characteristics }\end{array}$} & \multicolumn{2}{|c|}{ Willingness to pay } & \multirow{2}{*}{$\begin{array}{c}\text { Adjusted Odds Ratio } \\
\text { (95\% Confidence Interval) }\end{array}$} & \multirow[t]{2}{*}{ p-value } \\
\hline & $\begin{array}{l}\text { Yes } \\
\text { Frequency }(\%) \\
\end{array}$ & $\begin{array}{l}\text { No } \\
\text { Frequency }(\%) \\
\end{array}$ & & \\
\hline \multicolumn{5}{|l|}{ Age group (Years) } \\
\hline$\leq 20$ & $0(0.00 \%)$ & $60(100.00)$ & $0.0(<0.01-<0.01)$ & 1.00 \\
\hline $20-39$ & $27(13.20)$ & $177(86.80)$ & $0.82(0.40-1.71)$ & 0.60 \\
\hline \multirow[t]{2}{*}{$\geq 40$} & $54(30.70)$ & $122(69.30)$ & 1 & \\
\hline & $\mathrm{X}^{2}=34.82$ & $\mathrm{p}=<0.01$ & & \\
\hline \multicolumn{5}{|l|}{ Sex } \\
\hline Male & $40(20.70)$ & $153(79.30)$ & & \\
\hline \multirow[t]{2}{*}{ Female } & $41(16.60)$ & $206(83.40)$ & & \\
\hline & $\mathrm{X}^{2}=1.23$ & $\mathrm{p}=0.27$ & & \\
\hline \multicolumn{5}{|l|}{ Highest level of Education } \\
\hline Primary and below & $5(7.80)$ & $59(92.20)$ & $0.50(0.16-1.53)$ & 0.23 \\
\hline \multirow[t]{2}{*}{ Secondary and above } & $76(20.20)$ & $300(79.80)$ & 1 & \\
\hline & $X^{2}=5.50$ & $p=0.02$ & & \\
\hline \multicolumn{5}{|l|}{ Ethnicity } \\
\hline Yoruba & $66(17.80)$ & $305(82.20)$ & & \\
\hline Ibo & $15(25.40)$ & $44(74.60)$ & & \\
\hline \multirow{2}{*}{ Hausa } & $0(0)$ & $10(100.00)$ & & \\
\hline & $\mathrm{X}^{2}=4.28$ & $\mathrm{p}=0.12$ & & \\
\hline \multicolumn{5}{|l|}{ Occupation } \\
\hline Business/Trader & $32(19.80)$ & $130(80.20)$ & $0.61(0.27-1.39)$ & 0.24 \\
\hline Artisan & $22(21.80)$ & $79(78.20)$ & $0.50(0.23-1.07)$ & 0.08 \\
\hline Professional/Civil Servant/Teacher & $36(38.20)$ & $42(61.80)$ & $0.05(0.01-0.52)$ & 0.01 \\
\hline \multirow[t]{2}{*}{ Retiree/housewife/cleric/student } & $1(0.90)$ & $108(99.10)$ & 1 & \\
\hline & $X^{2}=40.96$ & $p=<0.01$ & & \\
\hline \multicolumn{5}{|l|}{ Marital Status } \\
\hline Married & $72(25.30)$ & $213(74.70)$ & $1.17(0.19-7.08)$ & 0.87 \\
\hline Single & $5(3.80)$ & $127(96.20)$ & $1.35(0.43-4.28)$ & 0.61 \\
\hline \multirow[t]{2}{*}{ Others* } & $4(17.40)$ & $19(82.60)$ & 1 & \\
\hline & $\mathrm{X}^{2}=27.72$ & $\mathrm{p}=<0.01$ & & \\
\hline \multicolumn{5}{|l|}{ Average monthly income } \\
\hline$<30000$ & $5(3.40)$ & $144(96.60)$ & $1.45(0.45-4.66)$ & 0.53 \\
\hline \multirow[t]{2}{*}{$\geq 30000$} & $76(26.10)$ & $215(73.90)$ & 1 & \\
\hline & $\mathrm{X}^{2}=33.99$ & $\mathrm{p}=<\mathbf{0 . 0 1}$ & & \\
\hline \multicolumn{5}{|l|}{ Wealth quintiles } \\
\hline First & $5(5.70)$ & $83(94.30)$ & 1 & \\
\hline Second & $6(6.80)$ & $82(93.20)$ & $1.21(0.32-4.60)$ & 0.79 \\
\hline Third & $8(9.10)$ & $80(90.90)$ & $1.14(0.32-4.12)$ & 0.84 \\
\hline Fourth & $14(15.90)$ & $74(84.10)$ & $2.22(0.66-7.44)$ & 0.20 \\
\hline \multirow[t]{2}{*}{ Fifth } & $48(54.50)$ & $40(45.50)$ & $9.57(2.88-31.82)$ & $<0.01$ \\
\hline & $X^{2}=99.32$ & $p=<0.01$ & & \\
\hline
\end{tabular}

$533 *$ : Divorced/Widowed, $\mathbf{p}<\mathbf{0 . 0 5}$ 
Figure 1

Sources of information on the prospective COVID-19 vaccine among community members in Ibadan, Nigeria

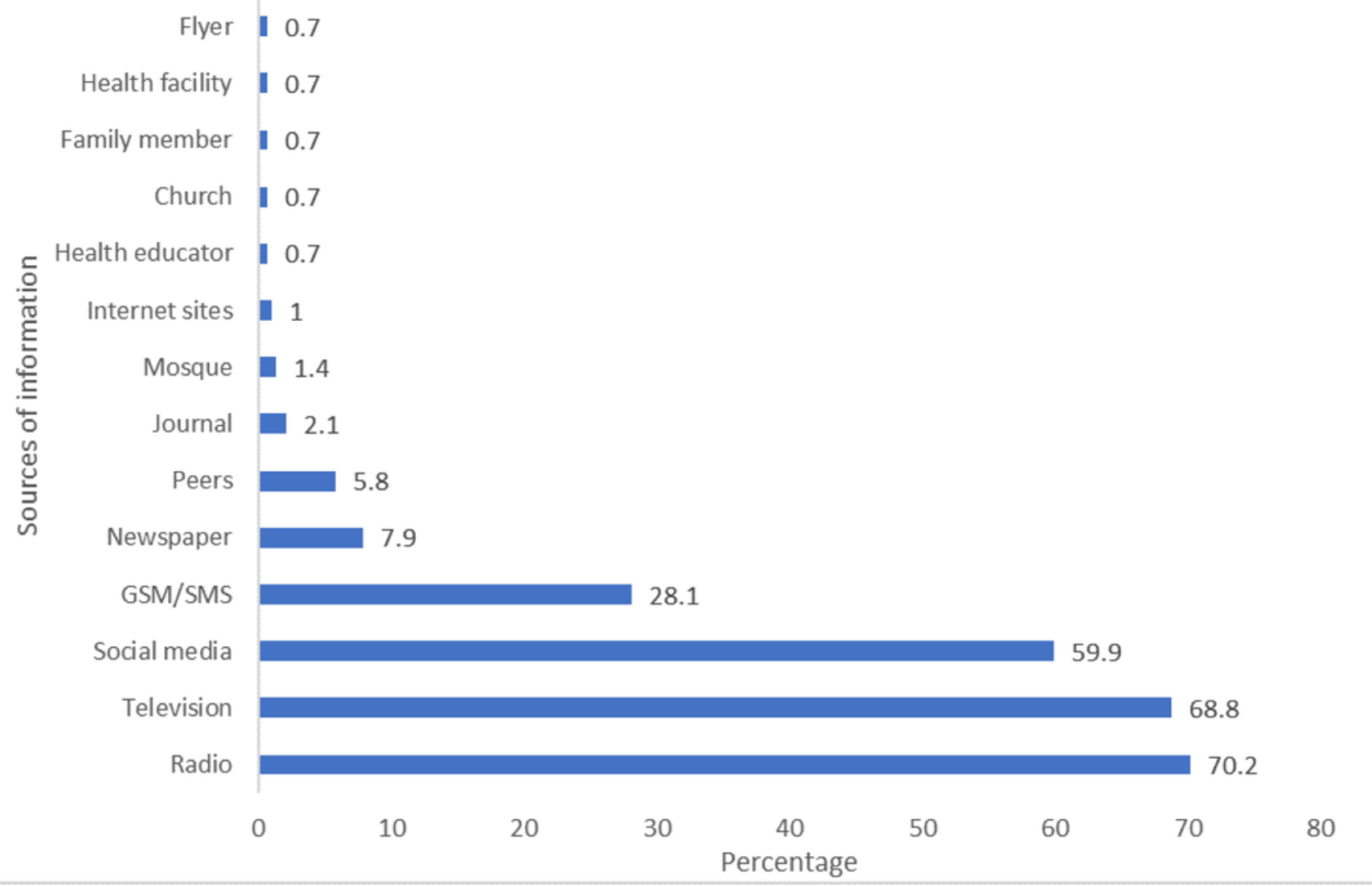




\section{Table $\mathbf{1}$ (on next page)}

Socio-demographic characteristics of community members in Ibadan, Nigeria 


\begin{tabular}{|c|c|c|c|c|}
\hline \multirow{2}{*}{$\begin{array}{l}\text { Socio-demographic Characteristics } \\
\text { Age group (Years) }\end{array}$} & \multirow[t]{2}{*}{ Frequency } & \multirow[t]{2}{*}{$\%$} & \multicolumn{2}{|c|}{ Confidence Interval } \\
\hline & & & Upper & Lower \\
\hline$\leq 20$ & 68 & 15.50 & 12.40 & 19.10 \\
\hline $21-40$ & 202 & 45.90 & 41.30 & 50.60 \\
\hline $41-60$ & 131 & 29.80 & 25.70 & 34.20 \\
\hline$>60$ & 39 & 8.90 & 6.60 & 11.90 \\
\hline \multicolumn{5}{|l|}{ Sex } \\
\hline Male & 193 & 43.90 & 39.30 & 48.50 \\
\hline Female & 247 & 56.10 & 51.50 & 60.70 \\
\hline \multicolumn{5}{|l|}{ Religion } \\
\hline Christianity & 293 & 66.60 & 61.40 & 70.20 \\
\hline Islam & 145 & 33.00 & 28.70 & 37.50 \\
\hline Traditional & 2 & 0.50 & 0.12 & 1.64 \\
\hline \multicolumn{5}{|l|}{ Highest level of Education } \\
\hline Primary and below & 64 & 14.50 & 11.60 & 18.10 \\
\hline Secondary and above & 376 & 85.50 & 81.90 & 88.40 \\
\hline \multicolumn{5}{|l|}{ Ethnicity } \\
\hline Yoruba & 371 & 84.30 & 80.60 & 87.40 \\
\hline Ibo & 59 & 13.40 & 10.50 & 16.90 \\
\hline Hausa & 10 & 2.30 & 1.20 & 4.10 \\
\hline \multicolumn{5}{|l|}{ Occupation } \\
\hline Business/Trader & 162 & 36.80 & 32.40 & 41.40 \\
\hline Artisan & 101 & 23.00 & 19.27 & 27.11 \\
\hline Professional/Civil Servant/Teacher & 68 & 15.50 & 12.38 & 19.13 \\
\hline Retiree/housewife/cleric/student & 109 & 24.80 & 20.97 & 29.01 \\
\hline \multicolumn{5}{|l|}{ Marital Status } \\
\hline Married & 285 & 64.80 & 60.20 & 69.10 \\
\hline Single & 132 & 30.00 & 25.91 & 34.44 \\
\hline Others* & 23 & 5.20 & 3.51 & 7.72 \\
\hline \multicolumn{5}{|l|}{ Average monthly income } \\
\hline$<30,000$ naira & 149 & 33.90 & 29.60 & 38.41 \\
\hline$\geq 30,000$ naira & 291 & 66.10 & 61.59 & 70.40 \\
\hline \multicolumn{5}{|l|}{ Wealth quintiles } \\
\hline First & 88 & 20.00 & 16.53 & 23.99 \\
\hline Second & 88 & 20.00 & 16.53 & 23.99 \\
\hline Third & 88 & 20.00 & 16.53 & 23.99 \\
\hline Fourth & 88 & 20.00 & 16.53 & 23.99 \\
\hline Fifth & 88 & 20.00 & 16.53 & 23.99 \\
\hline
\end{tabular}

1 *: Widowed/divorced 


\section{Table 2 (on next page)}

Perceptions on the prospective COVID-19 vaccine among community members in Ibadan, Nigeria 


\begin{tabular}{|c|c|c|c|c|}
\hline \multirow[t]{2}{*}{ Perception } & \multirow[t]{2}{*}{ Frequency } & \multirow[t]{2}{*}{$\%$} & \multicolumn{2}{|c|}{ Confidence interval } \\
\hline & & & Upper & Lower \\
\hline \multicolumn{5}{|c|}{$\begin{array}{l}\text { COVID-19 is a major public health problem requiring } \\
\text { vaccine (Total }=292 \text { ) }\end{array}$} \\
\hline Strongly Agreed & 281 & 96.20 & 93.38 & 97.88 \\
\hline Agreed & 2 & 0.70 & 0.19 & 2.46 \\
\hline Not decided & 3 & 1.00 & 0.35 & 2.98 \\
\hline Disagree & - & - & - & - \\
\hline Strongly disagreed & 6 & 2.10 & 0.95 & 4.41 \\
\hline \multicolumn{5}{|c|}{ COVID-19 vaccine will prevent COVID-19 $($ Total $=292)$} \\
\hline Strongly Agreed & 279 & 95.50 & 92.53 & 97.38 \\
\hline Agreed & 3 & 1.00 & 0.35 & 2.98 \\
\hline Not decided & 4 & 1.40 & 0.53 & 3.47 \\
\hline Disagree & - & - & - & - \\
\hline Strongly disagreed & 6 & 2.10 & 0.95 & 4.41 \\
\hline \multicolumn{5}{|c|}{$\begin{array}{l}\text { COVID-19 vaccine should get administered to everyone } \\
(\text { Total }=292)\end{array}$} \\
\hline Strongly Agreed & 209 & 71.60 & 66.15 & 76.44 \\
\hline Agreed & - & - & - & - \\
\hline Not decide & 11 & 3.80 & 2.12 & 6.62 \\
\hline Disagree & 26 & 8.90 & 6.15 & 12.73 \\
\hline Strongly disagreed & 46 & 15.80 & 12.02 & 20.37 \\
\hline \multicolumn{5}{|c|}{$\begin{array}{l}\text { COVID-19 vaccine is against our cultural belief } \\
(\text { Total }=\mathbf{2 3 8})\end{array}$} \\
\hline Strongly Agreed & 31 & 10.60 & 9.33 & 17.90 \\
\hline Agreed & 35 & 12.00 & 10.77 & 19.77 \\
\hline Not decide & 44 & 15.10 & 14.07 & 23.91 \\
\hline Disagree & - & - & - & - \\
\hline Strongly disagreed & 182 & 62.30 & 70.69 & 81.41 \\
\hline \multicolumn{5}{|c|}{$\begin{array}{l}\text { COVID-19 vaccine will save productive hours lost to } \\
\text { COVID-19 illness }(\text { Total }=\mathbf{2 9 2})\end{array}$} \\
\hline Strongly Agreed & 270 & 92.50 & 88.86 & 94.97 \\
\hline Agreed & 4 & 1.40 & 0.53 & 3.47 \\
\hline Not decided & 13 & 4.50 & 2.62 & 7.47 \\
\hline Disagree & - & - & - & - \\
\hline Strongly disagreed & 5 & 1.70 & 0.73 & 3.95 \\
\hline
\end{tabular}




\begin{tabular}{|c|c|c|c|c|}
\hline $\begin{array}{l}\text { COVID-19 vaccine will save money spent on COVID-19 } \\
\text { treatment }(\text { Total }=292)\end{array}$ & & & & \\
\hline Strongly Agreed & 272 & 93.20 & 89.66 & 95.52 \\
\hline Agreed & 3 & 1.00 & 0.35 & 2.98 \\
\hline Not decided & 12 & 4.10 & 2.37 & 7.04 \\
\hline Disagree & - & - & - & - \\
\hline Strongly disagreed & 5 & 1.70 & 0.73 & 3.95 \\
\hline \multicolumn{5}{|l|}{ I will take the vaccine when produced $($ Total $=292)$} \\
\hline Strongly Agreed & 180 & 61.60 & 55.95 & 67.04 \\
\hline Agreed & 4 & 1.40 & 0.53 & 3.47 \\
\hline Not decided & 76 & 26.00 & 21.33 & 31.35 \\
\hline Disagree & 9 & 3.10 & 1.63 & 5.75 \\
\hline Strongly disagreed & 23 & 7.90 & 5.31 & 11.54 \\
\hline \multicolumn{5}{|l|}{$\begin{array}{l}\text { COVID-19 vaccine will not have adverse health effects } \\
(\text { Total }=\mathbf{2 9 2})\end{array}$} \\
\hline Strongly Agreed & 133 & 45.50 & 39.93 & 51.28 \\
\hline Agreed & 3 & 1.00 & 0.35 & 2.98 \\
\hline Not decided & 147 & 50.30 & 44.64 & 56.04 \\
\hline Disagree & 2 & 0.70 & 0.19 & 2.46 \\
\hline Strongly disagreed & 7 & 2.40 & 1.17 & 4.86 \\
\hline
\end{tabular}

1 


\section{Table 3 (on next page)}

Willingness to pay for the COVID-19 vaccine and COVID-19 information required by community members in Ibadan, Nigeria 


\begin{tabular}{|c|c|c|c|c|}
\hline \multirow[b]{2}{*}{ Willingness to pay for the COVID-19 vaccine } & \multirow[t]{2}{*}{$\mathbf{n}$} & \multirow[t]{2}{*}{$\%$} & \multicolumn{2}{|c|}{ Confidence Interval } \\
\hline & & & Upper & Lower \\
\hline Yes & 81 & 18.40 & 15.07 & 22.30 \\
\hline No & 359 & 81.60 & 77.70 & 84.93 \\
\hline \multicolumn{5}{|l|}{$\begin{array}{l}\text { Maximum amount intended for payment } \\
(\text { Total }=81)\end{array}$} \\
\hline$<5000$ naira $(\$ 13.16)$ & 36 & 44.40 & 34.12 & 55.27 \\
\hline$\geq 5000$ naira $(\$ 13.16)$ & 45 & 55.60 & 44.73 & 65.88 \\
\hline \multicolumn{5}{|l|}{ Reasons for willingness* } \\
\hline To stay healthy & 81 & 100.00 & 95.47 & 100.00 \\
\hline To prevent loss of productive hours & 23 & 28.40 & 19.73 & 39.02 \\
\hline To prevent further treatment expenses & 23 & 28.40 & 19.73 & 39.02 \\
\hline To promote social acceptability of vaccines & 9 & 11.10 & 5.96 & 19.79 \\
\hline \multicolumn{5}{|l|}{ Reasons for unwillingness* } \\
\hline Costs not affordable by households & 359 & 100.00 & 98.98 & 100.00 \\
\hline Fear of adverse effects & 30 & 8.40 & 5.92 & 11.68 \\
\hline Fear of inaccessibility of vaccines & 2 & 0.60 & 0.04 & 2.38 \\
\hline Contrary to religious beliefs & 16 & 4.50 & 2.76 & 7.12 \\
\hline Contrary to culture & 1 & 0.30 & 0.01 & 1.31 \\
\hline \multicolumn{5}{|l|}{ Require specific information on COVID-19 vaccine } \\
\hline Yes & 275 & 62.50 & 57.89 & 66.90 \\
\hline No & 165 & 37.50 & 33.10 & 42.11 \\
\hline \multicolumn{5}{|l|}{ Information required before accepting COVID-19 vaccine* } \\
\hline Whether payments would be required & 248 & 90.20 & 86.09 & 93.16 \\
\hline Possible side effects of the vaccine & 175 & 63.60 & 57.80 & 69.10 \\
\hline Number of doses needed & 131 & 47.60 & 41.81 & 53.53 \\
\hline Whether the vaccine will prevent or cure COVID-19 & 90 & 32.70 & 27.45 & 38.48 \\
\hline Route of administration & 58 & 21.10 & 16.68 & 26.29 \\
\hline Age range of individuals to be vaccinated & 53 & 19.30 & 15.05 & 24.35 \\
\hline Manufacturer of the vaccine & 24 & 8.70 & 5.93 & 12.66 \\
\hline Vaccine collection points & 17 & 6.20 & 3.90 & 9.68 \\
\hline Duration of immunity provided & 11 & 2.50 & 2.25 & 7.02 \\
\hline Whether vaccination would be accompanied by incentives & 7 & 2.70 & 1.24 & 5.16 \\
\hline Vaccine's expiry date & 2 & 0.50 & 0.20 & 2.61 \\
\hline
\end{tabular}

\section{$1 \quad *$ : Multiple responses allowed


Table 4 (on next page)

Association between sociodemographic characteristics and willingness to pay for the prospective COVID-19 vaccine among community members in Ibadan, Nigeria 
1 Table 4: Association between sociodemographic characteristics and willingness to pay for the prospective 2 COVID-19 vaccine among community members in Ibadan, Nigeria

\begin{tabular}{|c|c|c|c|c|}
\hline \multirow{2}{*}{$\begin{array}{l}\text { Socio-demographic } \\
\text { Characteristics }\end{array}$} & \multicolumn{2}{|c|}{ Willingness to pay } & \multirow{2}{*}{$\begin{array}{c}\text { Adjusted Odds Ratio } \\
\text { (95\% Confidence Interval) }\end{array}$} & \multirow[t]{2}{*}{ p-value } \\
\hline & $\begin{array}{l}\text { Yes } \\
\text { Frequency (\%) }\end{array}$ & $\begin{array}{l}\text { No } \\
\text { Frequency }(\%)\end{array}$ & & \\
\hline \multicolumn{5}{|l|}{ Age group (Years) } \\
\hline$\leq 20$ & $0(0.00 \%)$ & $60(100.00)$ & $0.0(<0.01-<0.01)$ & 1.00 \\
\hline $20-39$ & $27(13.20)$ & $177(86.80)$ & $0.82(0.40-1.71)$ & 0.60 \\
\hline \multirow[t]{2}{*}{$\geq 40$} & $54(30.70)$ & $122(69.30)$ & 1 & \\
\hline & $X^{2}=34.82$ & $p=<0.01$ & & \\
\hline \multicolumn{5}{|l|}{ Sex } \\
\hline Male & $40(20.70)$ & $153(79.30)$ & & \\
\hline \multirow[t]{2}{*}{ Female } & $41(16.60)$ & $206(83.40)$ & & \\
\hline & $\mathrm{X}^{2}=1.23$ & $\mathrm{p}=0.27$ & & \\
\hline \multicolumn{5}{|l|}{ Highest level of Education } \\
\hline Primary and below & $5(7.80)$ & $59(92.20)$ & $0.50(0.16-1.53)$ & 0.23 \\
\hline \multirow[t]{2}{*}{ Secondary and above } & $76(20.20)$ & $300(79.80)$ & 1 & \\
\hline & $X^{2}=5.50$ & $p=0.02$ & & \\
\hline \multicolumn{5}{|l|}{ Ethnicity } \\
\hline Yoruba & $66(17.80)$ & $305(82.20)$ & & \\
\hline Ibo & $15(25.40)$ & $44(74.60)$ & & \\
\hline \multirow[t]{2}{*}{ Hausa } & $0(0)$ & $10(100.00)$ & & \\
\hline & $\mathrm{X}^{2}=4.28$ & $\mathrm{p}=0.12$ & & \\
\hline \multicolumn{5}{|l|}{ Occupation } \\
\hline Business/Trader & $32(19.80)$ & $130(80.20)$ & $0.61(0.27-1.39)$ & 0.24 \\
\hline Artisan & $22(21.80)$ & $79(78.20)$ & $0.50(0.23-1.07)$ & 0.08 \\
\hline Professional/Civil Servant/Teacher & $36(38.20)$ & $42(61.80)$ & $0.05(0.01-0.52)$ & 0.01 \\
\hline \multirow[t]{2}{*}{ Retiree/housewife/cleric/student } & $1(0.90)$ & $108(99.10)$ & 1 & \\
\hline & $X^{2}=40.96$ & $\mathrm{p}=<\mathbf{0 . 0 1}$ & & \\
\hline \multicolumn{5}{|l|}{ Marital Status } \\
\hline Married & $72(25.30)$ & $213(74.70)$ & $1.17(0.19-7.08)$ & 0.87 \\
\hline Single & $5(3.80)$ & $127(96.20)$ & $1.35(0.43-4.28)$ & 0.61 \\
\hline \multirow[t]{2}{*}{ Others* } & $4(17.40)$ & $19(82.60)$ & 1 & \\
\hline & $X^{2}=27.72$ & $\mathrm{p}=<0.01$ & & \\
\hline \multicolumn{5}{|l|}{ Average monthly income } \\
\hline$<30000$ & $5(3.40)$ & $144(96.60)$ & $1.45(0.45-4.66)$ & 0.53 \\
\hline \multirow[t]{2}{*}{$\geq 30000$} & $76(26.10)$ & $215(73.90)$ & 1 & \\
\hline & $X^{2}=33.99$ & $\mathrm{p}=<0.01$ & & \\
\hline \multicolumn{5}{|l|}{ Wealth quintiles } \\
\hline First & $5(5.70)$ & $83(94.30)$ & 1 & \\
\hline Second & $6(6.80)$ & $82(93.20)$ & $1.21(0.32-4.60)$ & 0.79 \\
\hline Third & $8(9.10)$ & $80(90.90)$ & $1.14(0.32-4.12)$ & 0.84 \\
\hline Fourth & $14(15.90)$ & $74(84.10)$ & $2.22(0.66-7.44)$ & 0.20 \\
\hline \multirow[t]{2}{*}{ Fifth } & $48(54.50)$ & $40(45.50)$ & $9.57(2.88-31.82)$ & $<0.01$ \\
\hline & $X^{2}=99.32$ & $p=<0.01$ & & \\
\hline
\end{tabular}

$3 \quad *$ : Divorced/Widowed, $\mathbf{p}<0.01$ 